\title{
DANÇANDO CONFORME A MÚSICA (OU CONFORME A LEI)?*
}

\author{
Márcia Maria Strazzacappa Hernandez \\ Universidade Estadual de Campinas, Campinas, SP, Brasil
}

\begin{abstract}
Resumo: O presente artigo propõe a discussão sobre a [estreita] relação entre dança e legislação que vem se construindo nos últimos anos no país e o quanto isso afeta a formação e a atuação dos artistas da dança (licenciados e bacharéis em dança) nos diferentes níveis da educação nacional. $\mathrm{O}$ artigo, embora traga resultados de algumas pesquisas concluídas, apresenta-se como um ensaio, buscando não perder a poesia que a maioria das discussões sobre arte demanda.
\end{abstract}

Palavras-chave: Dança. Ensino de dança. Formação do artistaprofessor. Lei de Diretrizes e Bases.

\section{PARA INICIAR A CONVERSA}

Desde 2001, ao assumir as disciplinas obrigatórias de Licenciatura em Dança da Faculdade de Educação da Universidade Estadual de Campinas (Unicamp), tenho como tema de pesquisa a formação do professor de dança, optando por trabalhar de forma integrada com a docência, a pesquisa e a extensão, e igualmente, respondendo ao desejo de não desmembrar a pesquisa acadêmica da pesquisa artística.

À época, iniciava-se no país um grande debate nacional sobre um projeto de lei que estava tramitando no congresso em Brasília após a criação de um conselho profissional federal de outra área do conhecimento que iniciou uma ingerência no campo de atuação dos artistas de dança. Foram anos de reuniões com a classe, criação de associações nacionais e regionais, realização de fóruns e encontros, pedido de vistas ao processo, audiências públicas em Brasília, dentre tantas outras ações que não vem ao caso aqui

\footnotetext{
* Artigo recebido em 4/11/2013 e aprovado em 24/1/2014.
} 
detalhar. Gostaria, no entanto, de destacar que em 2004, um dos coletivos de profissionais de dança do estado de São Paulo, o Instituto Dança SP, do qual fazia parte, realizou um evento denominado Encontro de Professores de Dança do Estado de São Paulo, na Oficina Cultural Oswald de Andrade. Esse encontro contou com a colaboração do grupo de estudo e pesquisa em educação e diferenciação sociocultural GEPEDISC da Faculdade de Educação da Unicamp, coordenado à época pela professora titular Liliana Segnini. A referida professora havia sido uma das responsáveis pela classificação da família dos artistas de dança na CBO 2002 (Classificação Brasileira de Ocupações do Ministério do Trabalho) da qual falarei mais adiante. Utilizando a mesma metodologia de classificação, o Instituto de Dança SP realizou um primeiro levantamento significativo dos diferentes espaços de atuação e formação dos profissionais de dança do estado. O encontro teve a participação de 120 inscritos, artistas de dança e professores, com diferentes formações e campos de atuação com o ensino de dança, tanto na educação formal quanto na educação não formal. Embora significativa, a análise se apresentou restrita, funcionando mais como uma amostragem.

Analisando a variedade da origem dos participantes desse encontro, ficou notório que a dança em São Paulo tem uma diversidade maior do que se imagina, em sua formação, locais de atuação e denominações. O encontro evidenciou que os artistas de dança conheciam apenas uma parte do universo e do mercado de trabalho, apontando para a necessidade de se aprofundar a análise. Como o Instituto era gerido por artistas voluntários e não tinha recursos financeiros, acabou encerrando suas atividades. Assim, o projeto de verticalizar a investigação foi engavetado, porém serviu de inspiração para uma pesquisa individual levada a cabo entre 2007 e 2009, financiada pelo CNPq, intitulada "Profissão: professor de dança".

A referida pesquisa visava analisar as condições de formação profissional [ou de vida] e atuação de professores de dança, tendo como recorte físico o estado de São Paulo e como recorte temporal, a década entre 1996 e 2006, isto é, após a implantação da Lei de Diretrizes e Bases da Educação Nacional (LDB 9394 de 20 de dezembro de 1996). A aludida lei indicava, entre outros, o ensino de arte como conteúdo obrigatório na Educação Básica e especificava o prazo de dez anos para seu cumprimento. Acompanhando a LDB, por sua vez, os Parâmetros Curriculares Nacionais da área de arte indicavam que a dança deveria ser contemplada ao lado das demais linguagens artísticas como o teatro, a música e as artes visuais. Esta mesma legislação especificava que todo(a) professor(a) de escola deveria ter diploma de licenciatura, o que poderia nos conduzir à crença de que apenas 
o licenciado em Dança estaria habilitado para ensinar dança nas escolas da educação formal, seja como conteúdo das aulas de Arte, seja como disciplina específica extracurricular, como encontrado em escolas particulares.

Recentemente, outro projeto de lei está em trâmite no Congresso, PL 7.032/10, que prevê, a exemplo da Lei da Música (n. 11.769/2008), a obrigatoriedade do ensino de dança e de teatro como disciplinas a serem ministradas nas escolas de ensino fundamental. Trata-se de um substitutivo que prevê a alteração do segundo e do sexto parágrafos, do artigo 26 da LDB 9.394, referente ao ensino da arte. A proposta é que o referido artigo passe a ter a seguinte redação:

"Art. 26 [...]

$\S 6^{\circ}$ As artes visuais, a dança, a música e o teatro são as linguagens que constituirão o componente curricular de que trata o $\$ 2^{\circ}$ deste artigo" (NR).

Art. $2^{\circ} \mathrm{O}$ prazo para que os sistemas de ensino implantem as mudanças decorrentes desta Lei, incluída a necessária e adequada formação dos respectivos professores em número suficiente para atuar na educação básica, é de cinco anos." (PL 7.032/2010)

Qual o impacto dessa lei para a educação no país? O que essa lei, caso aprovada, irá representar para os licenciados em dança? E para os artistas de dança? Temos cursos de licenciatura em dança (e em teatro) suficientes no país, capazes de formar professores destas linguagens específicas para abarcar todas as escolas num prazo de cinco anos? Estão previstos concursos para novos professores especialistas nas escolas? Ou seguiremos os mesmos passos trilhados pela música que, a toque de caixa (infelizmente não no sentido literal), professores de sala foram capacitados para trabalhar com essa linguagem? Ou seja, iremos dançar conforme a música?!

\section{PARA APRENDER COM EXPERIÊNCIAS ANTERIORES}

Vejamos a princípio o que ocorreu em meados de 2006, quando vencia o prazo de dez anos estabelecido pela Lei de Diretrizes e Bases da Educação Nacional para a adequação das escolas à legislação, lembrando que um dos pontos decisivos e impactantes da Lei dizia respeito à exigência de que todo professor da educação básica deveria ser portador de diploma de curso superior. Novos cursos de Pedagogia foram abertos em todo país, entre eles alguns à distância, visando diplomar, em curto prazo, professores em exercício, da rede pública e particular de ensino, que atuavam como professores da educação básica, já portadores do diploma técnico em Magistério. Foram cursos de todos os tipos, formatos e com diferentes níveis 
de qualidade. Não vou realizar análise crítica a esses cursos. No entanto, a título de ilustração para a discussão aqui proposta, trago o exemplo de projetos desenvolvidos na Unicamp.

A Faculdade de Educação ofereceu dois cursos especiais de Pedagogia, a saber: o Programa Especial de Formação de Professores em Exercício (PEFOPEX) e o Programa Especial de Formação de Professores em Exercício nas séries iniciais da educação fundamental da Região Metropolitana de Campinas e Cidades Adjacentes (PROESF). Ambos eram presenciais, de longa duração (três a quatro anos), e exigiam para a inscrição no processo seletivo (via vestibular específico) a apresentação do comprovante de que era professor ativo, como o contracheque ou a carteira de trabalho, e de que era portador do diploma de Magistério. As aulas ocorriam no período noturno e a diferença entre os dois cursos estava no número de turmas e nos docentes que ministravam as disciplinas. No primeiro, com uma única turma de 45 estudantes por ano, as aulas eram ministradas diretamente pelos docentes da Faculdade de Educação. No segundo, com dez turmas de 40 estudantes por ano, as aulas eram ministradas por assistentes pedagógicos selecionados após uma formação em curso de especialização anteriormente realizado.

Tanto o PEFOPEX quanto o PROESF seguiam a grade curricular dos cursos regulares de pedagogia da Faculdade de Educação, com exceção da carga horária referente aos estágios obrigatórios e da disciplina específica para tratar o corpo e a arte. No curso regular de Pedagogia há apenas uma disciplina intitulada "Educação, Corpo e Arte" (que já foi tema de comunicações orais em congressos como Endipe, Cole, Confaeb, entre outros). No currículo dos novos programas, foi possível criar um diferencial e a então “Educação, Corpo e Arte" foi desmembrada em duas novas disciplinas, separando os campos da Arte e da Educação Física. Assim, fui responsável pela organização da Teoria Pedagógica e Construção do Conhecimento em Arte oferecida no quinto semestre do curso. Esta disciplina tinha como ementa: "Estudo do viver cultural e social como expressões e linguagens da arte e da ciência. De caráter teórico e prático, introduz os alunos às diferentes linguagens corporais e/ou artísticas em suas relações com o processo educacional" (portal da FE). Era igualmente responsável pelas aulas magnas previstas na estrutura do curso. As aulas magnas eram palestras proferidas pelos professores supervisores das disciplinas ministradas no semestre, ou por convidados, uma vez por semana, para todas as 10 turmas juntas, no Salão Nobre da Faculdade de Educação ou no Centro de Convenções da Unicamp. Na disciplina específica de arte, contou-se com a presença de atores e atrizes, músicos, bailarinos e artistas plásticos, cada qual para falar da especificidade de seu fazer artístico. 
Um dos objetivos da disciplina era propiciar às professoras-estudantes (o feminino é proposital, pois era, de fato, um público exclusivamente formado por mulheres) o contato com a arte do espetáculo vivo, isto é, com a dança, o teatro e a música, para além das 200 horas de atividades científicoculturais propostas no próprio curso, segundo as exigências das Diretrizes Curriculares para os Cursos de Graduação em Pedagogia (2005) e demais cursos de formação de professores (licenciaturas específicas). Essa iniciativa pautava-se na crença de que o professorado, ao entrar em contato com um legítimo espetáculo cênico realizado em um real espaço teatral, com todo encantamento que a cena proporciona, seria afetado pela arte; logo, seria transformado por ela. No entanto, concluiu-se que não basta o contato se não houver a mediação.

Após termos oferecido a disciplina para quatro turmas do curso, mesmo se exigindo a presença em ao menos um único espetáculo artístico por semestre, poucos foram aqueles que chegaram de fato a transformar seus referenciais e a incorporar novos hábitos culturais. Ir ao teatro para assistir a um espetáculo de dança e/ou teatral definitivamente ainda não faz parte do cotidiano das professoras. (StRAZZACAPPA, 2007, p. 8)

Ao trabalhar diretamente com professores em exercício da rede de ensino, pude identificar de forma mais pontual a falta de informação que este público tem sobre dança. Afinal, a que tipo de dança estamos nos referindo, quando falamos sobre ensinar dança na escola?! Seria apenas a quadrilha da Festa Junina? Enquanto lecionava nos cursos, dei continuidade às minhas pesquisas, dentre elas uma sobre as "Visões e Crenças sobre ensino de arte das professoras da rede de ensino da Região Metropolitana de Campinas", realizada em 2007, por meio de bolsista PIBIC. Nesta, foi investigada a compreensão que as professoras participantes do curso PROESF tinham acerca do ensino de arte, tal como ele era abordado no espaço escolar. Para isso, foram analisadas as respostas sobre a questão de "arte" presente na prova de vestibular, especificamente preparada para o ingresso no curso. A pesquisa partiu da necessidade de confirmar uma suposição de que as professoras atuantes na educação básica desconheciam as linguagens artísticas a serem trabalhadas dentro do conteúdo arte, mesmo com a ampla divulgação dos documentos norteadores, dos Parâmetros Curriculares e dos Cadernos produzidos pelo estado. A desconfiança apenas se confirmou.

Por vezes, artistas da dança se mostram indignados com a falta de conhecimento, com as confusões, os mal-entendidos e os equívocos presentes e comuns sobre o campo de atuação da arte da cena. Entretanto, a pesquisa indicou que a postura do profissional de dança tem de ser a de 
esclarecer, informar, dar exemplos, pois não é culpa do cidadão comum a falta de conhecimento sobre um universo tão específico quanto a dança. Se para dançarinos que realizam uma formação profissional em escolas de dança (conservatórios e academias) o desconhecimento sobre determinados estilos (e/ou pior, o preconceito em relação a alguns) já existe, o que se dirá daqueles que não tiveram ao longo de sua vida contato com manifestações corporais nem assistiram a espetáculos, além do que está na mídia, nas novelas, na publicidade, nos programas de auditório, nos vídeos divulgados pelo Youtube?

Alguns anos mais tarde, a Faculdade de Educação ofertou um Curso de Especialização em Gestão Educacional (CEGE) para os gestores da rede pública do Estado de São Paulo, em uma empreitada hercúlea; afinal foram 6 mil participantes. Naquele momento, novamente, uma disciplina tematizando o corpo, a dança e a arte foi ministrada por uma equipe de 10 doutores e doutorandos do Laboratório de Estudos sobre Arte, Corpo e Educação (Laborarte). Foi igualmente produzido material didático como vídeo-aula e uma publicação em três volumes. Especificamente sobre arte, redigimos, a seis mãos, um capítulo intitulado"A construção do conhecimento em Arte" (Schroeder, Schroeder e Strazzacappa, 2005). A experiência foi mais que salutar, pois acabamos trazendo, pela primeira vez para os gestores, a experiência do movimento. $O$ trabalho pautou-se na compreensão que o conhecimento em arte demanda: necessariamente, a prática e a vivência da experiência. Como dizia Flávio Desgranges, autor que gosto sempre de citar, "é preciso educar, formar os formadores, propiciar experiência para se criar gosto por essa experiência. Propor processos apaixonantes para formar apaixonados" (DESGRANGES, 2003, p. 68).

Assim, após vivenciarem seus próprios corpos em movimento, gestores foram capazes de compreender alguns conceitos básicos no tocante à dança e ao seu ensino, como: a) a dança é uma área de conhecimento autônoma, isto é, que produz um conhecimento próprio; conhecimento cunhado no corpo em movimento do indivíduo, dele em contato consigo próprio e/ou em contato com o outro, com o espaço, ao som da música ou no silêncio; conhecimento sobre um coletivo, seja ele uma comunidade, uma região, uma nação; conhecimento como patrimônio imaterial, repleto de referências históricas, estéticas e simbólicas; expressão de indivíduos e de coletivos de uma dada comunidade; b) para o ensino de dança, são necessários espaços e equipamentos específicos; não é possível ensiná-la em qualquer lugar, como no chão sujo do refeitório, no pátio gramado da escola, em lugares de passagem de estudantes e demais agentes da escola; dança demanda experimentação, concentração, empenho e disciplina; repetição, ensaio e improvisação. 
Porém, saliento que a compreensão destes conceitos só foi possível porque gestores passaram pela experiência, ou, no sentido dado por Larrosa (1999), foram atravessados por ela.

\section{Para não Jogar o bebê com a ÁGUa do banho...}

Tenho buscado ao longo de meu trabalho como artista e educadora, averiguar nas situações encontradas e nos contextos dados [mesmo aqueles que foram alvo de duras e agudas críticas] o saldo positivo. Acredito ser importante "não jogar o bebê com a água do banho", permitindo-me aqui o uso de um ditado popular. Assim, identifico mais bônus que ônus nessas investidas legislativas.

Foi graças (mas não exclusivamente) às ingerências de um conselho federal de outra área do conhecimento que os artistas da dança do país (individualmente ou organizados em coletivos, institucionalizados ou não) se mobilizaram, se organizaram, aumentaram sua visibilidade e se fizeram ouvir. Os artistas da dança ainda enriqueceram suas produções artísticas e acadêmicas, ganharam força e conquistaram um espaço tanto na mídia quanto na mente do cidadão comum. Esse contexto todo proporcionou uma ampla discussão do campo do conhecimento, inclusive, sobre cursos superiores de dança no país.

Foi graças (mas não exclusivamente) ao Programa de Apoio a Planos de Reestruturação e Expansão das Universidades Federais (REUNI), criado pelo Decreto n. 6.096/2007, como "uma ação do plano de desenvolvimento da educação (PNE), instituído em reconhecimento ao papel estratégico das universidades - em especial do setor público - para o desenvolvimento econômico e social" (BRASIL, 2009), que passou a houver a abertura de novos cursos superiores de dança no país, sobretudo de licenciaturas, nas mais variadas regiões brasileiras. Destaca-se que, dentre os cursos novos abertos no programa, o de Licenciatura em Dança foi o que teve maior demanda, passando de 14 graduações, em 2003, para 43 cursos superiores. Constatouse que a criação destes cursos teve como consequência a abertura de concursos para docentes, doutores e mestres, titulados na área ou em áreas afins. Analisando o recém-instituído corpo docente das IESs, embora ainda composto por um número limitado de professores, observamos que muitos dentre eles são artistas, o que é desejado. Parto do princípio de que, nos cursos de formação de artistas, ser docente $e$ artista, seja uma condição necessária para uma boa prática formativa, para que não se "perca a mão", para que não se perca a alma da nossa profissão; em outras palavras, para que não nos distanciemos "daquilo de que somos feitos" (Strazzacappa, 2011, p. 145). 
Foi graças (mas não exclusivamente) à Lei da Música (n. 11.679/2008) que hoje temos em discussão um novo PL. Essa lei, que em 2008 criou polêmica, dividindo os ânimos entre os artistas, serviu de pano de fundo para o atual PL, que busca dar o mesmo nível de importância para as diferentes linguagens artísticas. Isso se coloca como um terreno fértil para outras e mais verticalizadas discussões, como as da reunião do CONFAEB e das demais associações de classe das linguagens específicas, tais como, a Associação Nacional de Pesquisadores em Artes Plásticas (ANPAP), a Associação Brasileira de Artes Cênicas (ABRACE) e a Associação Nacional de Dança (ANDA).

Foi graças (mas não exclusivamente) à LDB que professores em exercício, até então portadores de diplomas de nível médio de ensino (antigo Magistério), voltaram à sala de aula, desta vez, universitária; e cursaram Pedagogia, obtendo um diploma de nível superior. Tiveram a oportunidade de voltar a estudar, rever conceitos, construir novos paradigmas, e repensar sua prática profissional nas escolas em que atuavam. Tiveram a oportunidade de cursar disciplinas que tematizavam o corpo e a arte (pelo menos em algumas instituições de ensino superior), como anteriormente apontado.

\section{PARA PENSAR POSSIBILIDADES: LEI DA DANÇA}

À época efervescente dos enfrentamentos entre os artistas da dança e o Conselho Federal de Educação Física, cheguei a propor um estudo detalhado sobre uma lei francesa, denominada "Lei da Dança". A referida lei foi instituída em 1980 pelo governo francês, que passou a exigir de professores e instrutores de dança um Diplome d'État (diploma do estado), no qual foi definido o perfil do professor de dança e os conhecimentos mínimos necessários para se tornar um professor ou instrutor de dança no país. Além da definição do perfil e dos conteúdos, a lei francesa também definiu o que chamou de centros de excelência, ou seja, estabelecimentos de ensino de dança (escolas livres) que poderiam oferecer os cursos de formação de professores e a certificação dos mesmos.

Ao todo a França possui quatro centros de excelência. Questionamos se esse poderia ser um ponto de partida para uma Lei da Dança no Brasil? O que temos a aprender com o exemplo francês? Realizei um levantamento dos documentos referentes à implantação dessa lei, alguns dos quais hoje disponíveis em livros e outros acessíveis pela internet, pelo sítio do Centre de Documentation de La Danse, situado no Centre National de Danse Contemporaine de Pantin, cidade da periferia de Paris, França. Este centro agrupou em um único acervo toda a documentação referente à dança na França (história, espetáculos, legislação, ensino). 
Chamou a atenção constatar que os artistas da dança daquele país europeu foram igualmente vítimas da ingerência de outra área do conhecimento. Foi justamente esta ação que levou o Ministério da Cultura a criar a referida lei, para proteger os profissionais da dança e, sobretudo, para garantir a autonomia e a soberania da dança como arte e como um patrimônio imaterial do qual os franceses têm muito orgulho.

Quando propus o estudo mais detalhado sobre essa lei francesa, acreditava que esse poderia ser um modelo para um projeto nacional. Fui voto vencido e o estudo acabou engavetado. Dez anos se passaram após a primeira ação do conselho. Se naquela ocasião existiam apenas um pouco mais de uma dezena de cursos superiores de dança, hoje, como citado acima, no Brasil reúnem-se quarenta e três licenciaturas em dança, espalhadas pelas cinco regiões do país.

A atual conjuntura, em que um novo PL prevê um prazo de cinco anos para a implantação de disciplinas de dança e de teatro nas escolas brasileiras, desengaveto o estudo e fico a me perguntar se não seria essa uma possibilidade: identificar os centros de excelência no país para certificar os artistas da dança como professores, dando-lhes o direito de atuarem como especialistas nas escolas de educação básica. Não seria melhor o caminho de certificar quem já é profissional da dança do que o de capacitar o professor da escola em cursos de curta duração? Diplomar e assim valorizar quem já é profissional, quem foi se constituindo em uma vida no ofício?

Se observarmos com atenção a Classificação Brasileira de Ocupações, CBO2002, proposta pelo Ministério do Trabalho e Emprego (MTE), veremos que a ocupação de bailarino e dançarino, como eram então denominados os artistas da dança, pertenciam ao subgrupo identificado pelo título de "Profissionais de Espetáculos e das Artes", alocados na "Família 2622 - Artista da dança (exceto dança tradicional e popular)". Dentre as funções do artista da dança constam: dançar, interpretar, criar, coreografar, dirigir espetáculos, entre outras; e como suas atividades profissionais, temos: "ensinar dança; ministrar aulas magnas em dança; ensinar técnicas de dança para companhias profissionais; ensinar dança para amadores; ensinar técnicas corporais", dentre outras (CBO 2002).

Destaquei de forma proposital as atividades que abarcam o ensino que, em teoria, estariam em outra família junto aos profissionais do campo da educação e/ou junto ao campo do assistencialismo, como ocorre com os arte-educadores (mas isso é uma outra discussão). Evidencia-se que há uma clara distinção na classificação quanto aos termos função e atividade. A primeira indica finalidade; a segunda, possibilidade. Conclui-se assim que ensinar dança é uma atividade possível e quase que condição de ser artista 
da dança no Brasil. Sendo uma atividade prevista na CBO, não seria o caso de se pensar, finalmente, em proporcionar uma formação específica para o professor e o instrutor de dança no país? Da mesma forma como professores em exercício voltaram à sala de aula para obterem o diploma de pedagogos, artistas da dança não poderiam voltar à sala de aula em cursos especiais para se tornarem professores?

Ficam aqui algumas perguntas a serem pensadas. Espero que, com a presente reflexão, possa ter contribuído com algumas pistas. Vislumbro ainda um dia em que a dança ao invés de seguir a música ou a lei, tome a iniciativa e dê um primeiro passo.

\section{DANCING TO THE MUSIC (OR TO THE LAW)?}

ABSTRACT:This paper proposes a discussion on the narrow relationship between dance and legislation that has been built in recent years in Brazil and how this affects the formation and performance of dance personnel (with a Bachelor and Teaching Degree) at different levels of national education. Although the article provides results of some completed research, it is presented as an essay so as not to lose the poetry demanded by most discussions about Art.

KEY WORDS: Dance. Dance education. Dance teacher formation. LDB.

\section{¿DANZANDO DE ACUERDO CON LA MÚSICA (O DE ACUERDO CON LA LEY)?}

RESUMEN: El presente artículo propone la discusión sobre la [estrecha] relación entre la danza y la legislación que se ha construido en los últimos años en el país y en qué grado eso afecta a la formación y a la actuación de los artistas de la danza (licenciados y graduados en danza) en los diferentes niveles de la educación nacional. El artículo, aunque traiga los resultados de algunas investigaciones ya concluidas, es presentado como un ensayo, con la intención de no perder la poesía que la mayoría de las discusiones sobre el arte demanda.

Palabras claves: Danza. Enseñanza de danza. Formación del artista-profesor. Ley de Directrices y Bases.

\section{REFERÊNCIAS}

BRASIL. Lei de Diretrizes e Bases da Educação Nacional LDB 9.394. 1996.

MEC. Secretaria de Educação Fundamental. Parâmetros curriculares nacionais: arte. Brasília: MEC/SEF, 1997. 
MTE. Ministério do Trabalho e do Emprego. Classificação Brasileira de Ocupações (CBO). Brasília, 2002.

<http://www2.camara.leg.br/camaranoticias/noticias/EDUCACAO-ECULTURA/456284-EDUCACAO-APROVA-DANCA-E-TEATRO-COMO-DISCIPLINASOBRIGATORIAS-DO-ENSINO-BASICO.html>. Acesso em: 5 nov. 2013.

DESGRANGES, F. A pedagogia do espectador. São Paulo: Hucitec, 2003.

LARROSA, J. Pedagogia profana. Belo Horizonte: Autêntica, 1999.

STRAZZACAPPA, M. Daquilo de que somos feitos. In: ALBANO, A. A.; STRAZZACAPPA, M. (Org.). Entrelugares do corpo e da arte. Faculdade de Educação, Unicamp, 2011.

. Dança: outro aspecto da/na formação estética dos indivíduos. Anais da 30 reunião da ANPED, 2007.

STRAZZACAPPA, M.; SCHROEDER, J.; SCHROEDER, S. A construção do conhecimento em arte. In: BITTENCOURT, A.; OLIVEIRA JR. W. (Org.). Estudo, pensamento e criação. Livro 1, Ed. Unicamp, Campinas, 2005.

UNICAMP. Faculdade de Educação. Coordenação de Graduação. Cursos especiais. Proesf. Disponível em: <http://www.fe.unicamp.br/ensino/graduacao/proesf-curri. html >. Acesso em: 5 nov. 2013.

Márcia Maria Strazzacappa Hernandez é artista da dança e pedagoga. Mestre em Educação (Unicamp). Doutora em Artes-Estudos Teatrais e Coreográficos (Universidade Paris). Professora da Faculdade de Educação da Unicamp. Membro do Laborarte/FE/Unicamp. Bolsista de produtividade em pesquisa $\mathrm{CNPq}$. Coordenadora do GT educação $e$ arte/ANPED.

E-mail: marciastrazzacappa@yahoo.com.br 